\title{
APPLIED LINGUISTICS, METHOD AND OBJECTIVES IN LANGUAGE TEACHING
}

\author{
Sebastián Balet̂t
}

\section{Current assumptions}

At present there are many competing "methods" for the teaching of modern languages, most of which have one common characteristic - their underlying principles have been worked out either from theoretical linguistics or from the hypothetical nature of the process of language acquisition in the child, or from both. Method has been made to conform to theory, while such practical considerations as the appropriateness of method to objectives, students' interests and the nature and composition of classes have been left out of account. Fortunately, a mood of guarded scepticism as to the merits of methodology seems to be gaining ground. As Colin Wringe" points aut, "so-called 'modern methods' and progressive approaches of all kinds are held not to have produced the results promised by their proponents". That the concern -one is almost tempted to say the obsession- with "modem", "progressive" and "scientific" methods (and indeed with methodology itself) should be mainly confined to the teaching of moderns languages, as opposed to the teaching of, say, history, geography of biology, is perhaps a consequence of reasoning, from analogy. As every child leams its mother tongue easily, it is assumed that everybody must be capable of learning at least one foreign language. But as most people fail to learn a foreign language well (just as they fail to learn history, geography of biology well when at school), the problem is assumed to be one of method.

1 Wringe, Colin, Developments in Modern Language Teaching, lst edn, Open Books, London (1976). 


\section{SEBASTIAN BALET}

If only the right method could be found, language learning would be made easy for everybody. Moreover, language learning is just a skill (however intellectually stimulating), and everybody is capable of acquiring skills as opposed to concepts. The underlying argument from analogy leads to two further assumptions. In the first place, there is a widespread feeling that if the study of modern languages is somehow to be made "scientific", an intensive use of hardware and audio-visual aids is required. A second language should not be mainly learnt from books because it is assumed (wrongly) that a first language is not, and the urge to recreate real-life conditions has susprisingly led to the introduction of "language laboratories" (a misnomer if ever there was one). In the second place, there is the belief that languege teaching must be firmly rooted in linguistic theory, i.e., that a theoretical knowledge about language is a prerequisite to effective teaching. Hence the interest in applied linguistics and the assumption that the techniques of language teaching must be based on linguistic principles. Of course this is far from being a recent development. The Direct Method itself was the result of advances in linguistics, and particularly in phonetics, during the second half of the 19 th century. But never before had the purely empirical approach become so discredited, or the urge to provide theoretical foundations for language teaching been so strong. Thus, S. Pit Corder in his Introducing Applied Linguistics ${ }^{2}$ claims that "there can be no systematic improvement in language teaching without reference to the knowledge about languages which linguistics gives us". This contention, however, is open to serious objections. Paul Christophersen ${ }^{3}$, for instance, reminds us that there is no reason to believe that the units used in analysing language (in terms of pattern), are also those needed in learning it. Moreover, as W.F. Mackey ${ }^{4}$ has pointed out, if the theoretical linguist claims that such and such a method is the best way to learn a language, he is speaking outside his competence. Yet, modern linguistic theories, and particularly structuralism (in its American behaviuristic form) and transformational grammars, have been taken as the starting-point of what was assumed to be (rather naively as it has turned out) a complete revolution in language teaching methods.

\section{TG grammar and Structuralism}

The assumption that linguistics should condition language teaching is reinforced by reasoning from analogy along the lines inaugurated by the Natural Method to the effect that the concepts established in the study of first language acquisition can be carried over with little modification into the fields of second language learning. This view is also based on a generative grammar approach.

2 Pit Corder, S., Introducing Applied Linguistics, lst edn, Penguin Books, Harmondsworth (1973).

3 Christophersen, Paul, Second-Language Learning, Ist edn, Penguin Books, Harmondsworth (1973).

4 Mackey, W.F., Applied Linguistics, in English Language Teaching, vol. 20 (1966). 


\section{METHOD AND OBJECTIVES IN LANGUAGE TEACHIN}

Jakobovits ${ }^{5}$ contends that the learner is endowed with a set of language universals and a hypothesis-forming, creative ability which leads to the differentiation of grammatical categories and to the working out of general rules, and which operates both in first and second language acquisition. A more extreme position is exemplified by Saporta ${ }^{6}$, who claims that a knowledge of transformational grammar is essential to the writing of language courses because it offers the best possible description of how language works and of the underlying logical categories that make a universal grammar possible. From a more practical point of view, S. Pit Corder ${ }^{2}$ has suggested that TG grammar may be useful because it reveals the deep syntactic structure which is common to different surface patterns. As deep syntactic structures are relatively few, the learner might find it profitable to learn them together with the rules for transforming them into surface structures. This seems to be a particularly hypothetical approach, as the links between the assumed deep structures and the rich variety of actual performances must be very complex indeed. Such theoretical thinking is far removed from the practical demands of actual teaching. As I.A. Richards $^{6}$ has pointed out, though TG grammar purports to describe the language user's competence, that is to say, to generate an infinite range of utterances from a sort of built-in grammatical system, it does not follow that it can also help the foreign student to acquire that competence. Chomsky ${ }^{7}$ himself declared in 1968: "My own feeling is that from our knowledge of the organization of language and of the principles that determine language structure one cannot inmediately construct a teaching programme"; and the objections to linguistic theorising along TG grammar lines were aptly summarized by J.P.B. Allen $^{8}$ in vol. 3 of the Edimburgh Course in Applied Linguistics by poiting out that a theoretical description of competence does not necessarily lead to a more effective practical generation of performance.

The gulf between theory and practical demands is similarly obvious in the case of structuralism. The dangers of the structuralist approach to language learning through patterns or structures to be drilled repeatedly until they become estableshed as verbal habits have long been recognized, yet many modern textbooks are riddled with pattern drilling, substitution tables, multiple choice exercices, etc. Divorced from a situational meaning and taken out of an appropriate cultural context, structural exercises become, in the words of W.M. Ri-

5 Jakobovits, L.A., Implications of Recent Psycholinguistic Developments for the Teaching of a Second Language, in Language Learning, vol. 18, London (1968).

6 Saporta, S., Applied Linguistics and Generative Grammar, in Trends in Language Teaching, ed. by A. Valdman, McGraw-Hill, New York (1966).

7 Chomsky, Noam, Noam Chomsky and Stuart Hampshire Discuss the Study of Language, The Listener, 30th May, 1968.

8 Allen, J.P.B. Pedagogic Grammar, in Techniques in Applied Linguistics, vol. 3 of Edimburgh Course in Applied Linguistics, London (1974). 


\section{SEBASTIAN BALET}

vers", "soulless and useless". As Jakovobits ${ }^{3}$ has remarked, the number of patterns is almost infinite and it is impossible to drill the learner in all of them. Moreover, the disconnected nature of pattern drilling has been emphasized by Newmark ${ }^{10}$, who has pointed out that if each structural item had to be drilled and learnt separately, the child learner would be old before he could say a sin gle appropriate thing. But the essential flaw of structuralist courses, as seen for instance by C.H. Prator ${ }^{11}$, lies in their failure to operate in proper extralinguistic context: the have not solved the problem of moving "from language manipulation co communication".

\section{Theoretical justification of methods}

Both the structuralist approach, with its insistence on oral drills and TG grammar, based on a "universal grammar" present, as it were, in latent form in every child's mind, have led to an implicit revival of interest in the old Natural Method and there is much emphasis nowadays on the idea that the proper learning sequence should be listening, speaking, reading and writing. Hence the vogue of audio-visual courses and of the assumption that the medium of instruction should be the foreign language itself to the exclusion of the mother tongue and that the process of learning a foreign language should retrace the steps that have led us all to learn our native language. Hence also the rejection of "traditional" methods on the grounds that thet were not intended to teach the language but things about language, that they concentrated on the written language to the neglect of the spoken language (which theoretical linguistics claims to be the more important), and that they ignored, in teaching a foreign language to young people and adults, the principles involved in the process by which a child learns its mother tongue. As a result, most competing "up-to-date" courses are audio-visual and obviously give priority to the spoken language; they exclude the learner's mother tongue, are based on child psychology, make use of the units needed for describing the language in theoretical linguistics and incorporate the insight into the nature of language that transformational grammar is supposed to provide. In short, their guiding principles are both universal and theoretical. Universal because they are thought to apply to all language learning situations and theoretical because their effectiveness is deduced from linguistics and psychology instead of being ascertained through experimental research. As a result, in the existing morass of hypothetical assumptions and pronouncements, the basic common sense question of the relationship between method and aims, and more generally between overall objectives on the one hand and social needs and educational policies on the other tends to be completely submerged. Yet, language learning is not a unidimensional activity, as modern

10 Newmark, L., How not to interfere with Language Learning, in Language Learning, the Individual and the Process, ed. by E.W. Najam, Indiana University Press (1966).

11 Prator, C.H., English as a Second Language Teaching, in Teaching English as a Second Language, ed. by H.B. Allen, McGraw-hill, New York (1965). 


\section{METHOD AND OBJECTIVES IN LANGUAGE TECHING}

orthodoxy seems to take for granded. Language learning can take place in a variety of situations for a variety of purposes, and it may involve a great variety of learners with different interests and motivations. Theorists of language learning are prone to make their pronouncements in a sort of sociological vaccuum. They seem to have in view a class of ideal students whose minds constitute a receptive "tabula rasa", and they obviously believe that of all possible methods for second language teaching the best ones are those that can be theoretically justified. The ignore the complex factors inherent in the learner and in the learning situation and the fact that choice of method should not be conditioned by theoretical considerations alone.

\section{Principles and aims}

The conflict between different conceptions of language teaching is far from a recent development. From the very beginning of the history of second language learning we find a variety of conflictiong attitudes, approaches and methods. But, what is more important, we find a corresponding congruity between methods and objectives, which is now fashionably overlooked. The study of structure (i.e. grammar), of the spoken as apposed to the written language, the extrapolation from first language learning to second language learning, the distinction between learning the language and things about the language, are recurring constants in the history of second language learning. According to D.A. Wilkins ${ }^{12}$, "viewed historically, language teaching has always been subject to change, but the process of change has not resulted from the steady accumulation of knowledge about the most effective ways of teaching languages: it has been more the product of changing fashion. Viewed objectively, the process has resembled the swing of the pendulum". While agreeing that very little or no accumulation of knowledge has in fact taken place, I would suggest that the process of change has been due not so much to mere fashion but to successive methodological responses to changing objectives. The techniques which the Greeks developed for learning their mother tongue were adopted by the Romans and were later applied to the learning of Greek itself as a second language. The emphasis was on grammar and on the written language. Systematic rules were exemplified by means of texts of increasing complexity, extending to lines from the poets. But when these techniques were adopted by the Romans and applied to the learning of Greek, a new element was introduced, as the teachers were often native slaves who ensured a direct contact with the spoken language as well. Yet, the main purpose of the course was to teach the written language and, more specifically, the underlying structure which the language was supposed to have. This method was seemingly appropriate to the needs and aims

12 Wilking, D.A., Linguistics in Language Teaching, lst edn, Edward Arnold, London (1973). 
of Roman society, namely, a familiarity with Greek literature and thought through the written text, and secondarily a philosophical grasp of the logical categories embodied in language which were thought to be present in the human mind (an obviously Chomskian view). The needs of the unsophisticated tourist were not yet contemplated. In the Middle Ages, the study of Latin continued to be restricted to the written language. Grammatical rules were learnt by heart and classical and patristic texts were read and analysed. Yet, in England, as early as the late 10th century, Aelfric broke new ground in second language teaching with his Colloquy which, according to Stanley B. Greenfield $^{13}$ is the first example of the so-called Direct Method of language instruction. Written as a supplement to his Latin Grammar and Glossary, it was prompted by Aelfric's determination to keep alive the Latin tradition of the Church in perilous times ${ }^{13}$. When, in the late 13 th century, French began its slow decline as the predominant language of the English upper classes, and Walter of Bibbesworth wrote his little treatise to teach English children French, he took care to include a practical, everyday vocabulary organized round "centres of interest", and later adaptations of the work paid fuller attention to pronunciation ${ }^{14}$. Up to the Renaissance, the traditional approach, with such occasional modifications as were felt to be necessary, was probably suited to the objectives which second language learners had in mind. But when, in the 16 th century, new objectives were developed, there was a clash between aims and techniques and a strong reaction against traditional methods set in, which first became apparent in the teaching of Latin itself. Critics already objected to the teaching of language through grammar and in 1532 Di Marinis' brief grammar was published "to make Latinists and not grammarians out of the students", while Montaigne could boast that he has learnt his Latin without rules because his German tutor and his servants spoke to him only in that language. We find a similar reaction in the late 19th century against the "grammar-translation" method which had been perfected by Ahn and Ollendorf at the beginning of the century. With Claude Marcel's work, advocating oral comprehensión, followed by reading, speaking and writing, second language teaching was adapted to the new objective of learning a language for the purpose of understanding it when spoken and of speaking it fluently. With increased travelling facilities and the spread of education, the psychological method, the phonetic method and the direct method soon followed. The important thing to notice, however, is that at all times, the underlying principles are conditioned by stated or implied aims. The purpose of teaching Latin to students was to acquaint them with the written language and to provide them with an insight into the supposed structure of language. For this purpose, the study of grammar rules and their exemplification in disconnected sentences

13 Greenfild, Stanley B., Critical History of Old English Literature, Ist edn, University of London Press (1965).

14 Baugh, Albert C., A History of the English Language, 2nd edn, Routledge, London (1959). 


\section{METHOD AND OBJECTIVES IN LANGUAGE TECHING}

was perfectly reasonable and probably effective. Translation from Latin into the first language was equally justified, until the student reached a stage at which comprehension of the written text could be carried out without reference to the first language. Translation from the first language into Latin was a mot effective means of learning to apply grammatical rueles to the building of sentences. The traditional techniques for teaching Latin were subsequently applied to the teaching of modern languages because the aims had not changed. In the socio-economic conditions prevalent in Western Europe up to the mid-nineteenth century there was no need for the universal teaching of a second language, and much less for the teaching of the spoken language (and it is doubtful that there is any need today). Foreign languages were learnt, when learnt at all, mostly for the purpose of reading and corresponding. The translation method and the grammar-translation method seemed to satify this very restricted aim.

\section{Method should depend on objectives}

Choice of method should depend first and foremost on general objectives rather than on theoretical linguistics. The fundamental issues of why to teach, whom to teach and what to teach are seldom related to methodology and are indeed left to the vagaries of fashion, tradition or chance. Modern languages have been made part of the primary and secondary school curricula to the extent that in some continental countries, such as Spain, they are compulsorily and indiscriminately inflicted on all students both at primary and secondary levels. In England and attempt was made to introduce universal teaching of French at primary school level, but the conclusions of the 1974 Burstall Report ${ }^{15}$ certainly did not encourage the experiment. As to the question of why to teach school children a modern language (as opposed to that of teaching a modern language to people who are professionally interested in learning it), there seem to be two unwarranted assumptions. In the first place, it would appear that the traditional, mind-training role of Latin has been consciously or unconsciously transferred to modern languages, which are included in the curriculum because their study is supposed to be intellectually stimulating. Again, the Burstall report suggests that the study of a second language at primary school level does not result in any significant change in the students' intellectual and academic development. In the second place, languages are included in the curriculum for more utilitarian reasons. It is assumed that knoledge of at least one foreign language is a useful and almost obligatory accomplishment in the modern world. The question of the level of proficiency at which a foreign language begins to be useful, the further question of "useful" in what respects and for whom, and the problem of ascertaining the 
percentage of students who are capable of learning it up to the undertermined point at which it is useful to them in specific ways are left undiscussed. It is simply assumed that the majority of primary and secondary-school students profit, in a mysterious way, from their second language studies. With the present insistence on audio-visual courses and the spoken language, a second language is compulsorily imposed on unmotivated and ungifted students on the questionable ground that they will have the dubious privilege os speaking a few broken sentences in a foreign language if they ever decide to spend a week or a fortnight abroad later in life. The short-lived needs of the prospective tourist are apparently thought to be a sufficient justification for years of grudging and generally unavailing study on the part of the student and of enormous expense on the part of society. Of course, modern languages are thought to be useful in other ways as well, for reading and corresponding, etc.. But the point is that the spectrum of utility is left undefined, that students are lumped together irrespective of their special interests and motivations, that level of attainment in the light of specific aims is never investigated and, above all, that the choice of method is dictated, not by the utilitarian congruity between its natura and the nature of the learner's objectives, but by linguistic theory. Audio-visual, generative and structuralist methods are not chosen because they have been shown to be the most affective in attaining objectives (which have been left unspecified), but because they are believed to be intrisically better. The insistence on the pre-eminence of the spoken language does not come as a response to the ascertained usefulness of oral fluency for the majority of learners later in life, as opposed to the usefulness of, for instance, a command of the written language or of comprehension of the written text, but as a theoretical imperative imposed by the sort of analogical reasoning that leads to the Natural Method.

\section{Lack of experimental research}

The indiscriminate teaching of modern languages to all and sundry, the absence of carefully weighed objectives and of student selection in the light of both objectives and motivation, and the blind adherence to fashionable methods has inevitably resulted in the fact that, as Colin Wringel points out, "the current mood among modern language teachers is one of disillusion and uncertainty". Dissatisfaction with methodology now seems to became more and more widespread, but already in 1965 Politzer ${ }^{16}$ concluded that "success of failure in learning a language is not significantly influenced by the teaching method", and, in 1969, Lamendella ${ }^{17}$ declared that generative grammar was a complete failure in language teching. More recently, D.A. Wilking ${ }^{12}$ has stated the view

16 Politzer, R.L., Foreign-Language Learning, Prentice-Hall, London (1965).

17 Lamendella, J.T., On the Irrelevance of Transformational Grammar to Second-Language Pedagogy, in Language Learning, vol 19, (1969). 
that "method (is) less important than the teachers's competence" and has pointed out that "it is possible that linguistics is not even one of the most important elements in the preparation of a language teacher". But disillusion and uncertainty are likely to increase even further as it becomes ever clearer that the supposed authority of "modern" methods is based on mere speculation rather than on empirical research. It is now apparent that very little or no reasearch at all has been conducted into the effectiveness of different methods and techniques. This is hardly surprising, in view of the fact that, as D.A. Wilkins ${ }^{12}$ points out, there are so many parameters involved in conducting experimental research into the results of methodological choice that ultimate evidence may be for ever lacking. In the absence of facts, the merits and demerits of different theoretical approaches are discussed and "assessed" in a purely a priori fashion, thus opening the door to a massive use of pseudo-techniques which have nothing to recommend them apart from the fact that they are wrongly assumed to be justified by the recondite linguistic lore on which "modern" methods are based. I have in mind such things as "visual grammar", particularly in its transformational form, which very often becomes a stumblingblock rather than an aid. Misplaced ingenuity produces the most extraordinary and complex visual patterns which are no doubt intended to illustrate, and clarify, but in fact befog, intrinsically simple grammatical points. As for multiple-choice exercises, they acquaint the student with three of four situationally wrong, or grammatically mistaken, or idiomatically unsuitable or merely fantastic utterances for every correct one, so that they seem designed to teach an unpredictably abnormal language rather than the correct one.

\section{Objectives and traditional techniques}

While waiting for the results, if any, of experimental research, there seems to be no reason to discard traditional techniques out of hand. On the contrary, as some of the objectives which prompted them are, or should be, still valid, they may continue to play a useful role in language teaching. Such would be the case if, for instance, it was recognized that a limited ability to understand the written language may be more permanently rewarding than a limited ability to use the spoken language. The "centre of interest" and written translation may be found useful in vocabulary-building, a field of second language teaching which is neglected by modern methods with their insistence on patterns and transformations and with their exclusive concern with the limited vocabulary of the elementary spoken language. Yet, vocabulary-building is the most essential aspect of language learning and one of the most difficult. Such is probably the implication behind Locke's contention that the language student is to trust only his memory, a view that was made explicit by Henry Sweet ${ }^{19}$ when he declared that "the real intrisic difficulty of learning a foreign language lies in

18 Sweet, Henry, The Practical Study of Languages, Dent and Sons Ltd., London (1960 impression). 
that of having to master its vocabulary". As D.A. Wilkins ${ }^{12}$ points out "the fact is that while without grammar very little can be conveyed, without vocabulary nothing can be conveyed". The use of the "centre of interest" has the added advantage of drawing attention to the sociolinguistic context of language.

\section{Summary and conclusion}

In this short article, I have tried to draw attention to the following points:

a) Most current methods are based on theoretical principles derived from linguistics and child psychology.

b) Objectives are at present subordinated to methodology.

c) As the spoken language has been given theoretical preeminence by the linguistic principles which condition methodology, it is now imposed on learners irrespective either of its practical usefulness or of their interests and abilities.

d) There is no experimental evidence to support the claim that modern techniques are more effective than traditional ones.

e) Objectives should be re-defined and made dependent not on methodology but on practical considerations.

f) If methods were adapted to objectives, traditional techniques might continue to play a useful role in language teaching.

Progress in second language teaching will probably depend less on theoretical considerations than on such practical issues as reduction of class size; selection of students according to their respective interests once they have been acquainted with the whole spectrum of language-learning objectives; working for limited and specific aims; and exploiting to the full students' motivations. In the last resort, much will continue to hinge on the teacher's common sense and ability. 